significant different, absolute number of the Treg cells trended to decrease in patients treated with immunosuppressive agents. The use of IL-2 can effectively up-regulate Treg cells as well as increase Th17 to a certain extent, which restores the balance of Th17/Treg cells, but the long-term effect needs further investigation

Disclosure of Interest: None declared

DOI: 10.1136/annrheumdis-2018-eular.4203

\section{THU0413 NORMALISATION OF NAILFOLD MICROVASCULATURE AFTER HEMATOPOIETIC STEM CELL TRANSPLANTATION IN SEVERE SYSTEMIC SCLEROSIS}

M. Boonstra, D.C. Noordhoek, L.J. Beaart-van de Voorde, T.W. Huizinga, J.K. de Vries-Bouwstra. department of Rheumatology, Leiden University Medical Center, Leiden, Netherlands

Background: Microangiopathy in Systemic Sclerosis (SSc), as visualised by nailfold capillary microscopy (NCM), is a dynamic and sequential process. Uncontrolled case-reports and a case-series report possible improvement of nailfold microangiopathy after hematopoietic stem cell transplantation (HSCT).

Objectives: To evaluate differences in nailfold microvasculature in patients with severe SSc treated with HSCT and those treated otherwise.

Methods: Severe SSc was defined as fulfilling criteria of the ASTIS trial. ${ }^{1}$ For included patients two treatment groups were defined: 1. Patients treated with HSCT, 2. Patients treated otherwise (including cyclophosphamide, methotrexate, mycophenolate mofetil and rituximab). All available capillaroscopy images collected prior to and after treatment were scored independently by two trained observers, blinded for treatment. Scoring included categorical scores $(0=n o$ changes to $3 \geq 66 \%$ alterations per millimetre) for capillary loss, neoangiogenesis, haemorrhages, dilatations, giants, disorganisation, together with a qualitative pattern and a VAS score for overall severity of microangiopathy.

Results: In total 55 patients were included, of whom 33 were female, mean age was $50 \pm 13$ years and median mRSS of $20 .^{15-28}$ Twenty-nine patients were treated with HSCT. After treatment categorical score of capillary loss was lower with HSCT (median score 1.0 vs. 2.0, $\mathrm{p}=0.04$ ) and VAS scores for severity of microangiopathy were better with HSCT (50.0 vs. $67.3, p=0.03$ ). Compared to controls, a typical SSc pattern was less frequent in patients treated with HSCT $(n=12 / 22,55 \%$, vs. $n=18 / 20,90 \% p=0.01)$.

In 25 patients (HSCT $n=11$, control $n=14$ ) images prior to treatment were available. Improvement in capillary loss (HSCT -0.5 [IQR -1 to 0 ] vs. control +0.3 [IQR -1.0 to 1.0$] \mathrm{p}=0.01$; ), dilatation (HSCT $-1.5[\mathrm{IQR}-2.0$ to -1.0$]$ vs. control 0.0 [IQR -1.0 to 0.5$] \mathrm{p} \leq 0.01$ ) and VAS scores (HSCT median -32.5 [IQR -80.5 to -4.5 ] vs. - controls +2.0 [IQR -35.5 to +46.0$] p \leq 0.01$;) improved significantly more in the HSCT group.

Conclusions: In patients with severe SSc, microangiopathy as reflected by nailfold capillaroscopy images, is less severe after treatment with HSCT and shows more improvement over time compared to patients with severe SSc treated otherwise. In specific, improvement seems to be characterised by normalisation of the capillary diameter and capillary density. To our knowledge, this is the first study to report on changes in microangiopathy after HSCT in a controlled study design.

\section{REFERENCE:}

[1] van Laar JM, Farge D, Sont JK, Naraghi K, Marjanovic Z, Larghero J, et al. Autologous hematopoietic stem cell transplantation vs intravenous pulse cyclophosphamide in diffuse cutaneous systemic sclerosis: a randomized clinical trial. JAMA 2014;311(24):2490-8.

Disclosure of Interest: None declared DOI: 10.1136/annrheumdis-2018-eular.4651

\section{THU0414 ASSOCIATION OF THE ESOPHAGEAL DILATION AND INTERSTITIAL LUNG DISEASE ON CHEST HIGH RESOLUTION COMPUTED TOMOGRAPHY IN PATIENTS WITH IN SYSTEMIC SCLEROSIS: A CROSS-SECTIONAL STUDY}

F. Salaffi ${ }^{1}$, M. Di Carlo ${ }^{1}$, M. Carotti ${ }^{2}$, P. Fraticelli ${ }^{3}$, A. Gabrielli ${ }^{3}$, A. Giovagnoni ${ }^{2}$ ${ }^{1}$ Rheumatological Clinic, Università Politecnica delle Marche, Jesi; ${ }^{2}$ Clinic of Radiology; ${ }^{3}$ Medical Clinic, Università Politecnica delle Marche, Ancona, Italy

Background: Esophageal dilation and dysfunction has been implicated in the pathogenesis of interstitial lung disease (ILD) in systemic sclerosis (SSc).

Objectives: The aims of this were to explore the association of the esophageal dilation and ILD on chest high-resolution computed tomography (HRCT) in patients with SSc and to establish a cut-off point for the esophageal dilation suggestive for the presence of a significant SSc-ILD.
Methods: The widest esophageal diameter (WED) was obtained on axial HRCT images. The parenchymal abnormalities on HRCT were coded and scored according to Warrick method. Patient-centred measures, pulmonary function tests (PFTs) and the single breath carbon monoxide diffusing capacity of the lung (DLco) were also obtained. Multivariate regression analyses were performed to identify factors associated with esophageal diameter on HRCT.

Results: 126 subjects with SSc were included in the analysis. The mean $( \pm S D$ WED was $13.5( \pm 4.2) \mathrm{mm}$, and in $76(60.3 \%)$ partecipants WED was $>11 \mathrm{~mm}$ ILD was diagnosed 86 SSc patients (Warrick score $>7$ ), while in 40 subjects the lung findings were normal. SSc patients with ILD had larger mean esophageal diameter than those without lung disease $(19.4 \mathrm{~mm}$ vs. $14.1 \mathrm{~mm}, \mathrm{p}<0.001)$. We observed a high correlation between WED and Gastroesophageal reflux disease questionnaire (GerdQ) $(r=0.886, p<0.001)$, Borg score $(r=0.705, p<0.001)$, Warrick score $(r=0.614, p<0.001)$. WED negatively correlated with DLco $(r=-0.508$, $\mathrm{p}<0.001$ ). Multivariate analysis demonstrated positive associations between mean esophageal diameter and GerdQ $(p<0,0001)$, Borg index $(p<0.0005)$, and total Warrick score $(p=0.019)$.

Conclusions: In patients with SSc, an increased esophageal diameter (>11 mm) on chest HRCT is associated with pulmonary and esophageal symptoms, more severe ILD, and lower DLco.

\section{REFERENCES:}

[1] Vonk MC, van Die CE, Snoeren MM, Bhansing KJ, van Riel PL, Fransen $J$, et al. Oesophageal dilatation on high-resolution computed tomography scan of the lungs as a sign of scleroderma. Ann Rheum Dis 2008;67:1317-21.

[2] Richardson C, Agrawal R, Lee J, Almagor O, Nelson R, Varga J, Cuttica MJ, Dematte JD, Chang RW, Hinchcliff ME. Esophageal dilatation and interstitial lung disease in systemic sclerosis: A cross-sectional study. Semin Arthritis Rheum. 2016;46(1):109-4.

Disclosure of Interest: None declared

DOI: 10.1136/annrheumdis-2018-eular.4894

\section{THU0415 ANTI-PM/SCL ANTIBODY CLINICAL ASSOCIATIONS IN PATIENTS WITH SYSTEMIC SCLEROSIS. ANALYSIS OF THE MULTICENTER EUSTAR COHORT}

M.G. Lazzaroni ${ }^{1}$, A. Furloni ${ }^{1}$, I. Cavazzana ${ }^{1}$, S. Zingarelli ${ }^{1}$, F. Franceschini ${ }^{1}$, A. Tincani ${ }^{1}$, S. Bellando-Randone ${ }^{2}$, C. Caimmi ${ }^{3}$, E. Hachulla ${ }^{4}$, Y. Allanore ${ }^{5}$, P. Airo', on behalf of EUSTAR co-authors. ${ }^{1}$ University and Spedali Civili of Brescia, Brescia; ${ }^{2}$ University of Florence and Division of Rheumatology AOUC, Firenze; ${ }^{3}$ Azienda Ospedaliera Universitaria Integrata, Verona, Italy; ${ }^{4}$ University Lille Nord-de-France, Lille; ${ }^{5}$ University Paris Descartes and Cochin Hospital, Paris, France

Background: Antibodies to the PM/Scl complex are found in patients with Sys temic Sclerosis (SSc), but also with Polymyositis, Dermatomyositis and overlap syndromes. Historically, the main clinical association of anti-PM/Scl antibodies in SSc, which include calcinosis, articular and muscle involvement, and interstitial lung diseases, were described by some large single-centre studies, or by multicenter studies which recruited a relatively small number of positive patients. Therefore, some unresolved issue deserves further research. In particular, scleroderma renal crisis was recently identified in a sizeable number of anti-PM/Scl +SSc patients in a large monocentric British cohort (4 out of $70 ; 5.7 \%$ ), a somewhat unexpected finding since this antibody type is generally considered not to be associated with renal crisis.

Objectives: To evaluate clinical associations of anti-PM/Scl in patients with SSc in the large multicenter EUSTAR database, with specific focus on scleroderma renal crisis.

Methods: Patients from the EUSTAR database were included when the item anti-PM/Scl was fulfilled in at least one visit; clinical data were collected from the last visit available.

Results: Anti-PM/Scl status was available in 8,287 SSc patients from EUSTAR database: 295 were anti-PM/Scl +. After exclusion of 145 patients with multiple autoantibody positivity, 150 anti-PM/Scl+patients were compared with 7992 anti$\mathrm{PM} / \mathrm{Scl}$-negative patients. Among these, 2530 were positive for anticentromere, 1933 for anti-topoisomerase I, 186 for anti-RNA polymerase III, and 220 for antiU1Rnp antibodies.

Renal crisis was identified in 8 of 150 anti-PM/Scl+SSc patients $(5.3 \%)$, and was significantly more frequent than in anti-PM/Scl-negative SSc patients $(1.6 \%$; $\mathrm{p}=0.0015)$. Positivity for anti-PM/Scl was also associated with male sex, diffuse cutaneous subsets, joint and muscle involvement, lung fibrosis at chest X-rays heart conduction blocks, stomach and intestinal symptoms (table 1). However, in multivariate analysis, adjusted for age at disease onset, sex, and disease dura tion, the association of anti-PM/Scl with renal crisis was not significant, whereas 
the associations with joint and muscle involvement, lung fibrosis, and intestinal symptoms were confirmed (table 1).

Table 1 Results of the univariable and multivariable analysis adjusted on sex, age at disease onset and disease duration ( $n=8142$ patients). Results are presented as number/number available data (\%) unless stated otherwise.

\begin{tabular}{|c|c|c|c|c|c|c|}
\hline \multirow[b]{2}{*}{ Characteristics } & \multicolumn{3}{|c|}{ Univariable analysis } & \multicolumn{3}{|c|}{ Multivariable analysis } \\
\hline & Anti-Pm/scl- & Anti-Pm/Scl+ & $\begin{array}{c}p \\
\text { Value }\end{array}$ & $\begin{array}{l}\text { N available } \\
\text { data (\%) }\end{array}$ & OR $(95 \% \mathrm{Cl})$ & $\begin{array}{c}p \\
\text { Value }\end{array}$ \\
\hline $\begin{array}{l}\text { Age at disease onset (Years, } \\
\text { mean (SD) (n available) }\end{array}$ & $46.7(14.5)(6885)$ & $44.7(15.1)(140)$ & 0.081 & $7025(86.3)$ & 0.98 (0.90 to 0.99$)$ & 0.0015 \\
\hline $\begin{array}{l}\text { Disease duration (months, } \\
\text { mean (SD) (n available) }\end{array}$ & $152.2(107.6)(6874)$ & 129.5 (99.6) (139) & 0.052 & $7013(86.1)$ & $\begin{array}{l}0.997(0.995 \text { to } \\
0.999)\end{array}$ & 0.0136 \\
\hline Male sex & 1140/7992 (14.2) & $31 / 150(20.7)$ & 0.036 & $8142(100.0)$ & $\begin{array}{l}1.201(0.706 \text { to } \\
2.043)\end{array}$ & 0.4995 \\
\hline Caucasian ethnicity & 6462/7992 (20.9) & $126 / 140(90.0)$ & 0.332 & $8142(100.0)$ & & \\
\hline Raynaud's phenomenon & $6904 / 7549(91.5)$ & $146 / 150 \mid 97.3)$ & 0.016 & $7699(94.6)$ & & \\
\hline Oesophageal symptoms & $4317 / 766(56.4)$ & $93 / 150(62.0)$ & 0.190 & 7811 (95.9) & & \\
\hline Stomach symptoms & $1553 / 7337(21.2)$ & $49 / 150(32.7)$ & 0.008 & $7487(92.0)$ & & \\
\hline Intestinal symptoms & $1803 / 7587(23.8)$ & $63 / 150(42.0)$ & $<0.0001$ & 7737 (95.0) & $\begin{array}{c}2.894(1.890 \text { to } \\
4.430)\end{array}$ & $<0.0001$ \\
\hline Scleroderma renal crisis & $123 / 7605(1.6)$ & $8 / 150(5.3)$ & 0.0015 & 7755 (95.2) & $\begin{array}{c}1.489(0.525 \text { to } \\
4.219)\end{array}$ & 0.4540 \\
\hline Diffuse cutaneous subtype & $1990 / 7412(54.7)$ & $55 / 148(45.3)$ & 0.022 & 7560 (92.9) & $\begin{array}{l}0.825(0.525 \text { to } \\
1.296)\end{array}$ & 0.4033 \\
\hline Active digital ulcers ever & $2597 / 4973(52.2)$ & $66 / 126$ (52.3) & 0.97 & $5099(62.6)$ & & \\
\hline Joint synovitis & $734 / 7411(9.9)$ & $34 / 149(22.8)$ & $<0.0001$ & 7560 (92.9) & $\begin{array}{l}2.963(1.199 \text { to } \\
3.215)\end{array}$ & 0.0073 \\
\hline Joint contractures & $2191 / 7152(29.9)$ & $64 / 149(43.0)$ & 80.0001 & $7301(89.7)$ & & \\
\hline Tendon friction rubs & $404 / 7087(5.8)$ & $14 / 149(9.4)$ & $<0.0001$ & 7236 (88.9) & & \\
\hline Muscle weakness & $1177 / 7512(15.7)$ & $59 / 148(39.9)$ & 80.0001 & $7660(94.1)$ & & \\
\hline Muscle atrophy & $668 / 7334(9.1)$ & $37 / 148(25.0)$ & $<0.0001$ & 7482 (91.9) & & \\
\hline CKelevation & $380 / 6259$ (6.1) & 47/140(33.6) & $<0.0001$ & $6399(78.6)$ & $\begin{array}{c}6.695(4.181 \text { to } \\
10.720)\end{array}$ & $<0.0001$ \\
\hline Conduction blocks & $880 / 5333(16.5)$ & $35 / 131(26.7)$ & 0.029 & $5464(67.1)$ & $\begin{array}{c}1.468(0.905 \text { to } \\
2.382)\end{array}$ & 0.1199 \\
\hline Elevated SPAP (ECHO) & $976 / 5592(17.5)$ & $19 / 137(13.9)$ & 0.33 & $5729(70.4)$ & & \\
\hline Lung fibrosis on plain X-rays & $64 / 117(54.7)$ & $1542 / 4527(51.6)$ & $<0.0001$ & $4644(57.0)$ & $\begin{array}{c}2.512(1.629 \text { to } \\
3.872)\end{array}$ & $<0.0001$ \\
\hline
\end{tabular}

Conclusions: In the largest series of anti-PM-Scl positive patients so far reported, well-known clinical associations were confirmed. Moreover, scleroderma renal crisis was more frequent than in the antibody-negative patient controls (which included a majority of anticentromere-positive patients, and a relatively small number of anti-RNA polymerase III-positive patients). However, this association was probably explained by covariates, such as joint and muscle involvement, or lung fibrosis. A possible role of corticosteroid therapy might therefore be suspected.

REFERENCE:

[1] Bruni C, et al. Rheumatology (Oxford). 2017;56:317-8.

Acknowledgements: Authors would like to thank the non-profit organisation 'Gruppo Italiano Lotta alla Sclerodermia' (GILS) for its substantial grant for this research project.

Disclosure of Interest: None declared

DOI: 10.1136/annrheumdis-2018-eular.4301

\section{THU0416 VERTEBRAL FRACTURE PREVALENCE AND MEASUREMENT OF THE SCANOGRAPHIC BONE ATTENUATION COEFFICIENT ON CT SCAN IN 70 PATIENTS WITH SYSTEMIC SCLERODERMA}

M. Fauny ${ }^{1}$, E. Bauer ${ }^{1}$, E. Albuisson ${ }^{2}$, J. Perrier-cornet ${ }^{1}$, J. Deibener ${ }^{2}$, F. Chabot ${ }^{2}$, D. Mandry ${ }^{2}$, O. Huttin ${ }^{2}$, I. Chary-valckenaere ${ }^{1}$, D. Loeuille ${ }^{1} .{ }^{1}$ Rheumatology; ${ }^{2} \mathrm{CHU}$ Nancy, Vandoeuvre Les Nancy, France

Background: Osteoporosis screening is not systematic in sclerodermic patients but some studies demonstrated a similar risk between rheumatoid arthritis and systemic scleroderma. ${ }^{1,2,3}$ Thoracic and/or TAP (thoraco-abdomino-pelvic) CT (Computed Tomography) scans are classically performed in the follow-up of scleroderma, mainly to evaluate lung involvement.

Objectives: To study vertebral fracture (VF) prevalence and the scanographic bone attenuation coefficient of the first lumbar vertebra (SBAC-L1) on CT scans in systemic scleroderma patients. Secondary objectives are to study specific risk factors of SBAC-L1 $\leq 145$ Hounsfield Units (HU) and to evaluate SBAC-L1 measurements reliability.

Methods: This monocentric retrospective study included patients followed from 2000 to 2014 and fulfilling ACR/EULAR 2013 criteria for systemic scleroderma and who underwent a thoracic or TAP CT scan. Osteoporotic risk factors, Dual Energy X-ray Absorptiometry (DXA) measurements and clinical characteristics were collected. For CT scan, the VFs were determined according to Genant's classification on sagittal sections. The SBAC-L1 was measured in Hounsfield Units $(\mathrm{HU})$ on axial section of $\mathrm{L} 1$ in a Region of Interest drawed in trabecular bone. Intra- and inter-reader reliabilities for SBAC-L1 were calculated. An SBAC $\mathrm{L} 1 \leq 145 \mathrm{HU}$ (fracture threshold) was used to define patients at risk of VF. ${ }^{4}$ Predictive factors for VF or SBAC-L1 $\leq 145 \mathrm{HU}$ were studied.

Results: A total of 70 patients were included (mean age: $62.3( \pm 15.6)$ years, women $88.5 \%$, diffuse scleroderma $22.9 \%(n=16))$ in the study. Sixty patients $(85.7 \%)$ presented with at least one clinical risk factor for osteoporosis. Eighteen patients $(25.7 \%)$ received vitaminocalcic supplementation and $10(14.3 \%)$ received antiresorptive therapy. DXA was only performed on 30 patients $(42.8 \%)$ and $5(16.7 \%)$ of them presented a T-score $\leq-2.5$ DS. 3 VFs were detected in 3 patients $(4.3 \%)$. The mean SBAC-L1 was $157.26 \mathrm{HU}( \pm 52.1)$, and 35 patients (50\%) presented a SBAC-L1 $\leq 145 \mathrm{HU}$. SBAC-L1 measurements were highly reliable (Kappa $>0.9$ for both intra- and inter-reader reliability). For the univariate analysis, a SBAC-L1 $\leq 145 \mathrm{HU}$ was significantly associated with age (OR=1.09, C 95\%: 1.04-1.13), calcinosis (OR=6.3, $\mathrm{Cl} 95 \%: 1.61-24.75)$ and periarticular calcifications $(\mathrm{OR}=3.22, \mathrm{Cl} 95 \%$ : 1.06-9.77). For the multivariate analysis, age (especially patients older than 63 years), calcinosis and acro-osteolysis were independently associated with a SBAC-L1 $\leq 145 \mathrm{HU}$.

Conclusions: On a large sample of sclerodermic patients with clinical risks of osteoporosis, only $42.8 \%$ were screened for DXA and $16.7 \%$ of them were osteoporotic. The VF prevalence on CT scan was $4.3 \%$ and the SBAC-L1 measurement identified $50 \%$ of the population at the fracture threshold. The presence of calcinosis, periarticular calcifications or acro-osteolysis should lead to an osteoporosis screening, especially for patients under 63 years old.

\section{REFERENCES:}

[1] Avouac J. Arthritis Care Res (Hoboken). 2012 Dec;64(12):1871-8.

[2] Yuen SY. J Rheumatol. 2008 June;35(6):1073-8.

[3] Kilic G. Int J Rheum Dis 1 avr 2016;19(4):405-11.

[4] Pickhardt PJ. Ann Intern Med 2013;158(8):588-95.

Disclosure of Interest: None declared

DOI: 10.1136/annrheumdis-2018-eular.1501

\section{THU0417 WHOLE BODY DISTRIBUTION AND CLINICAL ASSOCIATIONS OF TELANGIECTASIA IN SYSTEMIC SCLEROSIS: A CROSS-SECTIONAL STUDY}

M. Jouvray ${ }^{1}$, D. Launay ${ }^{1}$, S. Dubucquoi ${ }^{2}$, V. Sobanski ${ }^{1}$, C. Podevin ${ }^{3}$, M. Lambert $^{1}$, S. Morell-Dubois ${ }^{1}$, H. Maillard ${ }^{1}$, P.-Y. Hatron ${ }^{1}$, E. Hachulla ${ }^{1}$, J. Giovannelli ${ }^{3}$.

${ }^{1}$ département de médecine interne et immunologie clinique; ${ }^{2}$ Institut d'Immunologie: ${ }^{3}$ Centre de Référence des Maladies Autoimmunes et Systémiques Rares du Nord et Nord-Ouest de France (CeRAINO), CHU Lille, Lille, France

Background: Telangiectasia (TA), one of the diagnostic criteria for systemic sclerosis (SSc), could be a clinical marker for the severity of vasculopathy, including pulmonary hypertension $(\mathrm{PH})$.

Objectives: We designed a cross-sectional study: (i) to describe the whole-body distribution of TA, (ii) to assess the associations between the whole-body number of TA and the characteristics of patients, (iii) to determine whether the number of TA may be useful to discriminate SSc-PH patients.

Methods: Patients were included in the National Referral Centre for Rare Systemic And Autoimmune Diseases if they fulfilled the 2013 ACR/EULAR criteria for SSc. They were excluded if they had received laser treatment. The whole-body number and distribution of TA were recorded at inclusion. The associations were studied using univariate, adjusted and multiple linear regressions.

Results: 106 patients were enrolled, including 12 with $\mathrm{PH}$. The median (interquartile range) number of TA was 30 (82.7). Their distribution was: $37.2 \%$ on the face, $33.2 \%$ on the upper limbs including $26.4 \%$ on the hands, $28.1 \%$ on the trunk including $17.1 \%$ for the upper part of the trunk, and $1.5 \%$ on the lower limbs. Using multivariate linear regression model, the whole-body telangiectasia number was independently associated with male gender (percentage change $(95 \% \mathrm{Cl})=$ $+144.4 \%$ (7.5; 455.9), $p=0.033)$, pulmonary hypertension $(+162.8 \%(5.6 ; 553.8)$, $\mathrm{p}=0.038)$, history of pulmonary embolism $(+336.4 \%(39.0 ; 1270.1), p=0.012)$, glomerular filtration rate $\left(-1.6 \%(-3.2 ;-0.1)\right.$ per $1 \mathrm{ml} / \mathrm{mn} / 1.73 \mathrm{~m}^{2}$ increase, $\left.p=0.038\right)$ and soluble endoglin $(+28.2 \%(1.2 ; 62.5)$ per $1 \mathrm{ng} / \mathrm{ml}$ increase, $\mathrm{p}=0.039)$. The $\mathrm{ROC}$ analyses assessing the ability of telangiectasia to discriminate the presence of pulmonary hypertension revealed that the area under the curve was significant for the telangiectasia number on the whole body $(0.77(0.57 ; 0.88))$, on the hands and face $(0.81(0.57 ; 0.91))$ and on the hands $(0.77(0.57 ; 0.89))$. 